\title{
Siddiq, Abdur R. and Kennedy, Andrew R. (2015) Porous poly-ether ether ketone (PEEK) manufactured by a novel powder route using near-spherical salt bead porogens: characterisation and mechanical properties. Materials Science and Engineering: C, 47 . pp. 180-188. ISSN 0928-4931
}

\author{
Access from the University of Nottingham repository: \\ http://eprints.nottingham.ac.uk/34449/8/PEEK\%20Paper\%20MSE-C.pdf
}

\section{Copyright and reuse:}

The Nottingham ePrints service makes this work by researchers of the University of Nottingham available open access under the following conditions.

This article is made available under the Creative Commons Attribution Non-commercial No Derivatives licence and may be reused according to the conditions of the licence. For more details see: http://creativecommons.org/licenses/by-nc-nd/2.5/

\section{A note on versions:}

The version presented here may differ from the published version or from the version of record. If you wish to cite this item you are advised to consult the publisher's version. Please see the repository url above for details on accessing the published version and note that access may require a subscription.

For more information, please contact eprints@nottingham.ac.uk 
Porous Poly Ether Ether Ketone (PEEK) manufactured by a novel powder route using near-spherical salt bead porogens: Characterisation and mechanical properties

Abdur R. Siddiq, Andrew R. Kennedy

Manufacturing Research Division, Faculty of Engineering, University of Nottingham, University Park, Nottingham, NG7 2RD, UK

\#Tel: +44 1159513744

\#Email: andrew.kennedy@nottingham.ac.uk 


\begin{abstract}
Porous PEEK structures with approximately $85 \%$ open porosity have been made using PEEK-

OPTIMA ${ }^{\circledR}$ powder and a particulate leaching technique using porous, near-spherical, sodium chloride beads. A novel manufacturing approach is presented and compared with a traditional dry mixing method. Irrespective of the method used, the use of near-spherical beads with a fairly narrow size range results in uniform pore structures. However the integration, by tapping, of fine PEEK into a pre-existing network salt beads, followed by compaction and "sintering", produces porous structures with excellent repeatability and homogeneity of density; more uniform pore and strut sizes; an improved and predictable level of connectivity via the formation of "windows" between the cells; faster salt removal rates and lower levels of residual salt. Although tapped samples show a compressive yield stress > $1 \mathrm{MPa}$ and stiffness $>30 \mathrm{MPa}$ for samples with $84 \%$ porosity, the presence of windows in the cell walls means that tapped structures show lower strengths and lower stiffnesses than equivalent structures made by mixing.
\end{abstract}

\title{
Keywords
}

PEEK; porosity; powder processing; characterisation; compressive strength 


\section{Introduction}

Permanent, porous biomaterial structures have the ability to provide a transitional space between bone and a biomaterial substrate (which provides the main structural support) and an appropriate level and geometry of porosity will enable bone in-growth and hence enhanced integration between the bone and the biomaterial structure. Poly-ether-ether ketone (PEEK) has attracted wide interest as a material from which a porous medical device could be made [1]. The benefits of PEEK include; exceptional strength and stiffness for a thermoplastic polymer, excellent chemical resistance and bio-passive behaviour, $\mathrm{X}$-ray translucence and excellent wear properties which match with medical implant requirements [2-8]. Despite the fact that PEEK is not bioactive, direct bone, cartilage and fibrous contacts with PEEK implants have been observed in ovine models, although the bonding is expected to be via mechanical interlocking rather than chemical [9]. Although porous PEEK structures show better implant-cortical bone contact than solid, it is recognised that enabling processes may be required for PEEK to compete directly with porous metals for chemical ossiointegration [1].

With appropriate consideration during the design of a medical device incorporating porous features, for example for an inter-body cage for spinal fusion, the porous structure need not support the inter-lumbar pressure (which is of the order of 0.5-1.0 MPa depending upon activity $[10,11])$. That said; the porous element must be sufficiently robust to be handled and implanted without plastic deformation or fragmentation. The strength and stiffness of porous structures follow so-called "scaling laws" [12] where the relative stiffness and strength are related to the relative density (or solid fraction) through a constant and a power law exponent. Whilst specific targets for optimum pore fractions and sizes for implant fixation via bone in-growth remain largely undefined [13], previous studies focussing on the same target application as in this work, have sought to mimic trabecular bone, with porosity close to $80 \%$ and a mean pore diameter of roughly $700 \mu \mathrm{m}$ [1]. Design of an appropriate porous structure, however, necessitates a balance between achieving sufficient strength and adequate pore spaces for bone in-growth.

The production of porous structures via the removal of a pore forming or space holding (porogen) phase within a solid structure offers the greatest potential to control pore size and porosity whilst achieving a high level of pore homogeneity [14-17]. A number of researchers have used salt ( $\mathrm{NaCl})$ porogens in combination with several different processing methods to produce porous polymer structures: for instance, gas foaming [18]; concurrent electro-spinning [19], gas anti-solvent precipitation [20] and phase-separation [21], that tend to exhibit a wide range of irregularly-sized and shaped pores. Whilst good progress has been made, problems still persist with this method, owing to the demand for high quality and reproducible parts associated with the target application. Central to this is the difficultly in mixing or interspersion of large, irregularly-shaped salt particles, with a wide distribution in sizes, with liquids or fine powders. The homogeneity of the resulting mixture is thus difficult to control both within a part and from part-to-part.

The most promising structures, in terms of pore homogeneity and interconnectivity, have been achieved using rounded or spherical porogens [22,23], in one case using additional sintering of the packed bed of porogen to increase the connectivity between particles and hence between pores in the resultant porous structure [23]. Examples of typical porous structures resulting from these techniques are presented in Figure 1, but unfortunately there is no indication of how repeatable the 
processes are, how uniform or homogenous the porosity and structures are, or quantification of the connectivity of the structure.

In both of the aforementioned studies [22,23], interspersion of the polymer into the porous preform was affected by infiltration with a polymer solution. Unfortunately the limited solubility of PEEK in suitable solvents means that porous PEEK scaffolds cannot be made in the same way and an alternative approach is required. Although porous PEEK samples have been made by a number of different methods (reviewed in [1]), particulate leaching methods are commonly preferred. Irrespective of the process used, achieving structures that mimic trabecular bone, with an appropriate level of pore interconnectivity and adequate mechanical strength has been difficult [1] and is additionally problematic from a processing perspective given the high melting point of PEEK $\left(345^{\circ} \mathrm{C}[24]\right)$ and the lack of suitable solvents. This study aims to demonstrate a process that can greatly enhance the quality and reproducibility of interspersion of PEEK powder into a bed of $\mathrm{NaCl}$ beads and hence of the density and interconnectivity of the porous product. Some preliminary mechanical tests have also been undertaken to determine their suitability as implantable structures.

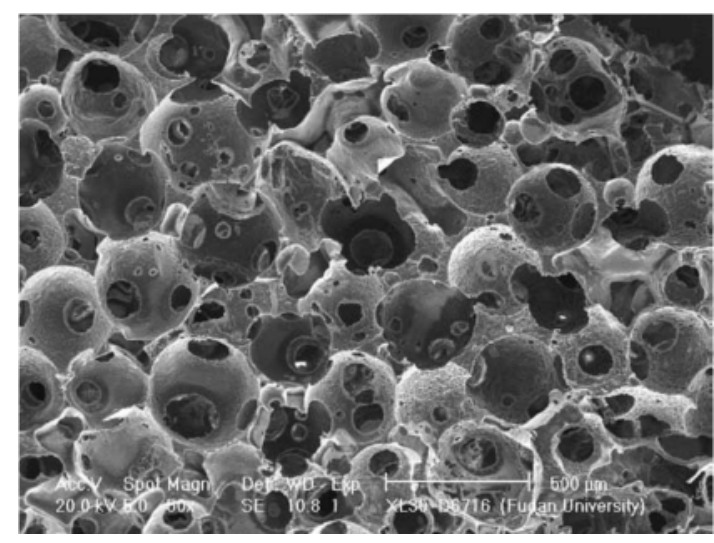

(a)

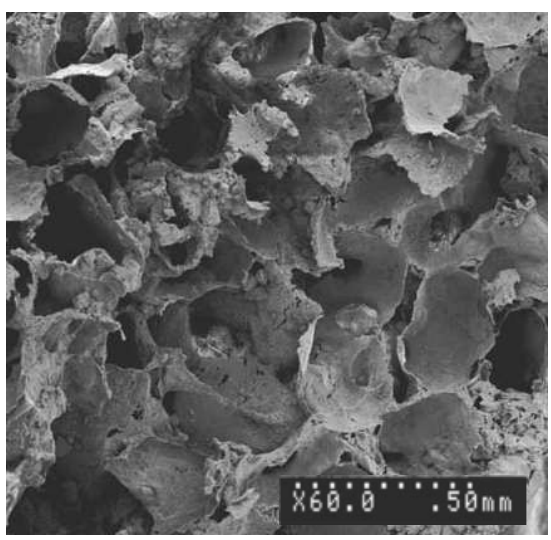

(b)

Figure 1: SEM micrographs of (a) PLGA scaffolds made using 355-450 $\mu \mathrm{m}$ diameter paraffin spheres [22] and (b) PLLA-reinforced apatite scaffolds manufactured using 300-500 $\mu \mathrm{m}$ rounded salt particles [23]

\section{Experimental procedure}

Sodium chloride ( $\mathrm{NaCl}$ or salt) powder with $99.5 \%$ purity was processed into near-spherical beads (with an aspect ratio of $1.14 \pm 0.02$ ) using a method outlined in $[25,26]$. Beads with diameters between 1.0 and $1.4 \mathrm{~mm}$ were selected by sieving. PEEK-OPTIMA ${ }^{\circledR}$ LT1 PEEK powder was used and was supplied by Invibio Ltd. The morphologies of the beads and the PEEK powder are shown in Figure 2. The PEEK particle size distribution was measured using a Malvern Mastersizer 2000 instrument, yielding an average diameter $\left(D_{50}\right)$ of $54 \mu \mathrm{m}$, with a range $\left(D_{10}\right.$ and $\left.D_{90}\right)$ of 21 and 110 $\mu \mathrm{m}$ respectively. The densities for the two components were $1.3 \mathrm{~g} \mathrm{cc}^{-1}$ for the PEEK and $1.65 \pm 0.05$ $\mathrm{g} \mathrm{cc}^{-1}$ for the (23\% porous) $\mathrm{NaCl}$ beads (as measured in [26]). The packing behaviour for the powders was studied using a Quantachrome Autotap machine, by tapping a known mass of powder in a 
graduated measuring cylinder. The apparent and tap densities for the powders were 0.90 and $0.97 \mathrm{~g}$ $\mathrm{cc}^{-1}$ for the salt beads (packing fractions of 0.55 and 0.59 respectively) and 0.37 and $0.42 \mathrm{~g} \mathrm{cc}^{-1}$ for the PEEK (packing fractions of 0.28 and 0.32 respectively).

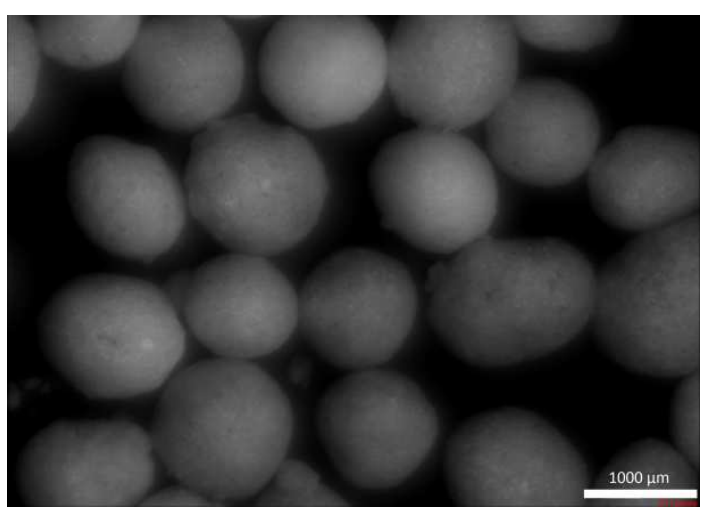

(a)

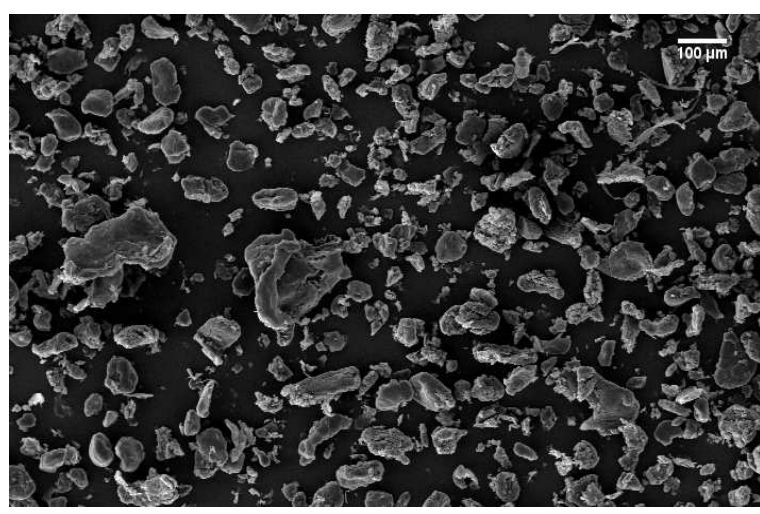

(b)

Figure 2 (a) Near-spherical salt beads with diameters between 1.0-1.4 mm and (b) PEEK powder

In order to achieve porosity in excess of $80 \%$, consideration of the powder densities led to a 1:6 mass ratio of PEEK to salt beads being used (leading to an estimated $83 \%$ porosity in the PEEK scaffold after salt removal). Two distinct processing methods were used, both involving a "mixing" process followed by compaction, sintering (or melting), salt dissolution and drying. The "mixing" methods differed, namely dry mixing of the PEEK and salt or tapping of the PEEK through a bed of salt beads (a schematic of the process steps is shown in Figure 3 ). 


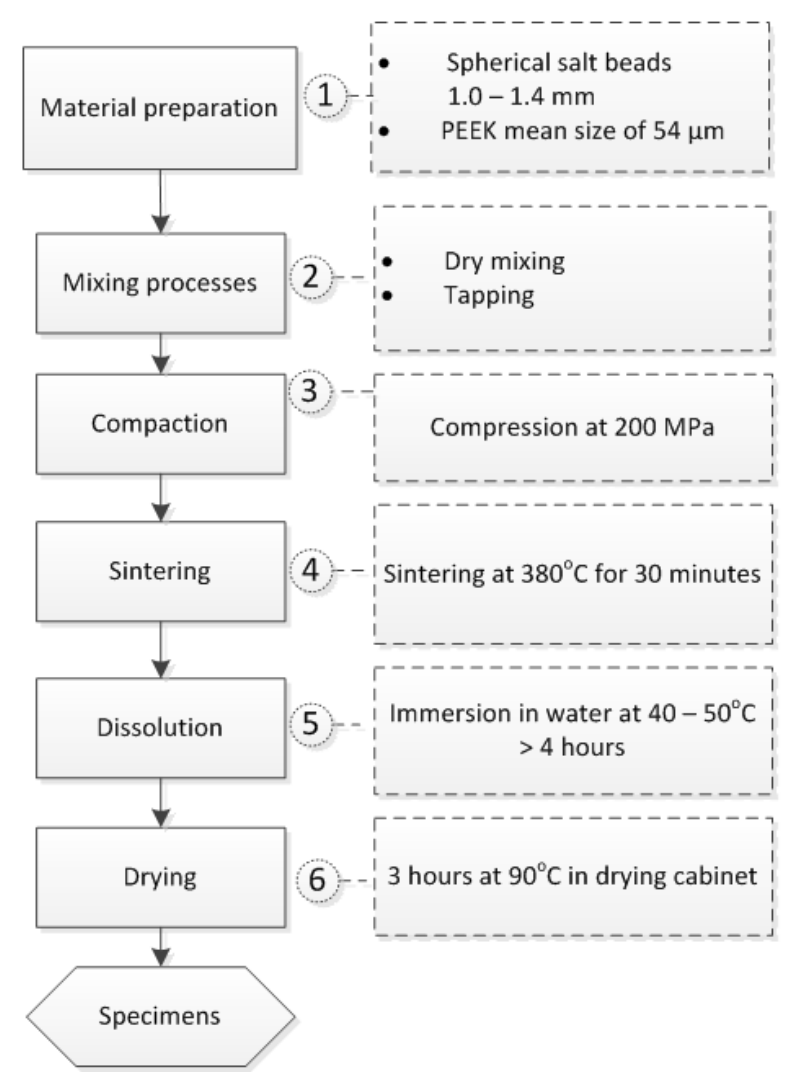

Figure 3: Schematic of the experimental methods for fabricating porous PEEK specimens

A dry mixing process was used to intersperse the salt beads and the PEEK powder. $42 \mathrm{~g}$ of salt beads were mixed with $7 \mathrm{~g}$ of PEEK powder in a Turbula mixer for $15 \mathrm{~min} .4 .9 \mathrm{~g}$ of the mixed powders was then poured into a die for subsequent compaction. Difficulties in achieving a homogeneous mixture of the dry powders were evident, as was their capacity to segregate during handling and transfer into the die. Every effort was made to minimise segregation through careful mixing, handling and transfer methods.

PEEK and $\mathrm{NaCl}$ beads were also combined using a tapping-based process previously applied to metal powders [25]. In this process, $4.2 \mathrm{~g}$ of salt beads were poured into the cavity of a $22 \mathrm{~mm}$ diameter die (with the bottom punch in place) and packing was enhanced by brief tapping using the same Autotap machine as described earlier. $0.7 \mathrm{~g}$ of PEEK powder was then place on top of the bed, where after the top punch was inserted. The whole assembly was then tapped, using the same machine, which employs a simple lifting and dropping action, stopping after a pre-determined number of cycles (approximately 6000). An image of the tooling and a schematic of the layered structure and the tapping direction (marked with an arrow) are given in Figure 4.

After both interspersion methods, uniaxial die compaction was performed at a pressure of roughly $200 \mathrm{MPa}$ to produce a robust PEEK-NaCl "composite" pellet. The pelleted samples were sintered at $380^{\circ} \mathrm{C}$ for $30 \mathrm{~min}$ and, when cool, were immersed in warm $\left(40-50^{\circ} \mathrm{C}\right)$ water to dissolve the salt for a minimum of $4 \mathrm{hr}$ and subsequently dried at a maximum of $90^{\circ} \mathrm{C}$ for a minimum of $3 \mathrm{hr}$. 


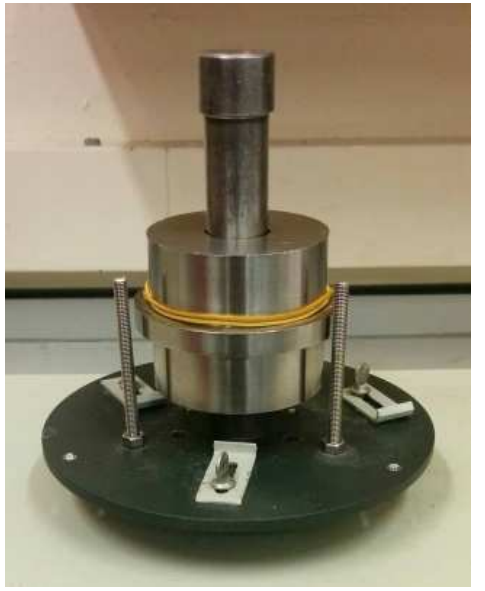

(a)

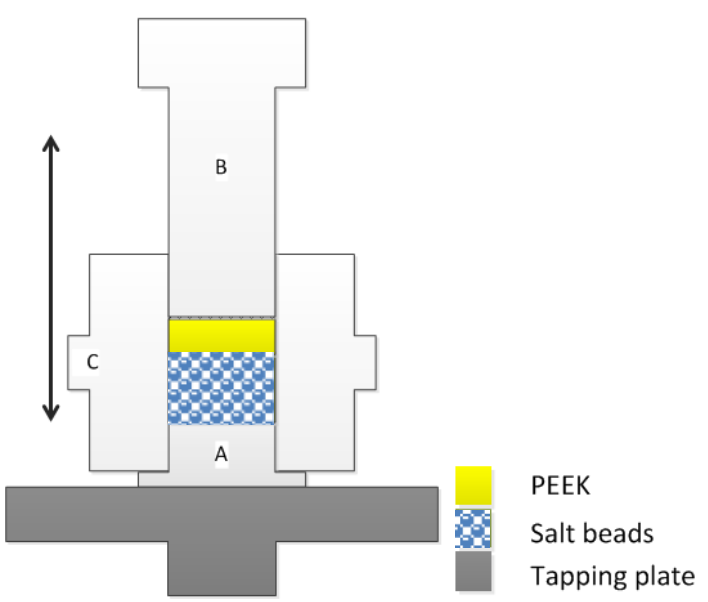

(b)

Figure 4: (a) Tapping tooling and (b) schematic of the powder layers (the arrow shows the tapping direction, $A, B$ and $C$ are the lower and upper punch and die respectively)

Scanning electron microscopy (SEM) was used to analyse the PEEK scaffold morphology. Sectioned PEEK scaffolds were sputter coated with platinum prior to examination. The pore morphology was quantified using X-ray micro-computed tomography (CT) on a Scanco Medical $\mu \mathrm{CT} 40$ instrument. Compressive testing of the foams was performed using an Instron Universal Testing machine, compressing samples $22 \mathrm{~mm}$ in diameter and $5 \mathrm{~mm}$ in height. Samples were deformed at a rate of $0.5 \mathrm{~mm} \mathrm{~min}^{-1}$, testing a minimum of 6 samples per type. In order to measure the stiffness, twin extensometers were used to accurately measure the compressive strain during multiple unloading and reloading cycles after initial loading to $75 \%$ of the compressive yield point.

\section{Results and discussion}

\subsection{General Observations}

For the tapping process, loading the beads and tapping creates a packed bed with height of roughly $11.3 \mathrm{~mm}$ (the same as that predicted from the powder mass and the tapped packing fraction). An additional approximately $5 \mathrm{~mm}$ thick layer of PEEK was then applied on top. After the tapping was completed (defined by when further tapping produces no further detectable migration of the PEEK manifested by no change in the position of the top punch in the assembly) the final height of the combined powder bed was roughly $11.8 \mathrm{~mm}$, indicating that nearly all the PEEK had been tapped into the void space in the bead structure and that an above-optimum mass ratio (of PEEK to $\mathrm{NaCl}$ ) was used. It was calculated that the PEEK filled the void space created by the packed beads with a packing fraction of 0.29 , lower than the 0.32 for tapped PEEK in an "infinite" vessel, no doubt affected by the scale and morphology of the pores relative to the size of the PEEK powder.

During compaction the void spaces between the PEEK particles and between the $\mathrm{NaCl}$ beads are removed, creating, for both cases, a compact with a density of $1.85 \mathrm{~g} \mathrm{cc}^{-1}$, albeit in the case of the tapped sample with a PEEK layer on the surface. For the simpler case of the dry mixed sample, 
without a PEEK layer, the fact that the compact density exceeds the theoretical density for the mixture $\left(1.59 \mathrm{~g} \mathrm{cc}^{-1}\right)$, indicates some densification of the porous salt beads (to an estimated $1.97 \mathrm{~g}$ $\mathrm{Cc}^{-1}$ and $8 \%$ porosity). It has been observed that for beads alone, compacted at the same pressure, a density of $2.02 \mathrm{~g} \mathrm{cc}^{-1}$ is achieved; indicating that bead densification is possible.

The bottom surfaces of compacted pellets made by both mixing methods are shown in Figure 5, from which it is clear that PEEK powder has migrated through the packed bed of $\mathrm{NaCl}$ beads. It is also apparent from these images that the distribution of salt beads is much more uniform for the tapped structure, with bead-rich and bead-depleted regions being much more prominent for compacts made by dry mixing and compaction. In both cases there was no evidence for cracking or fragmentation of the beads as a result of the compaction process.

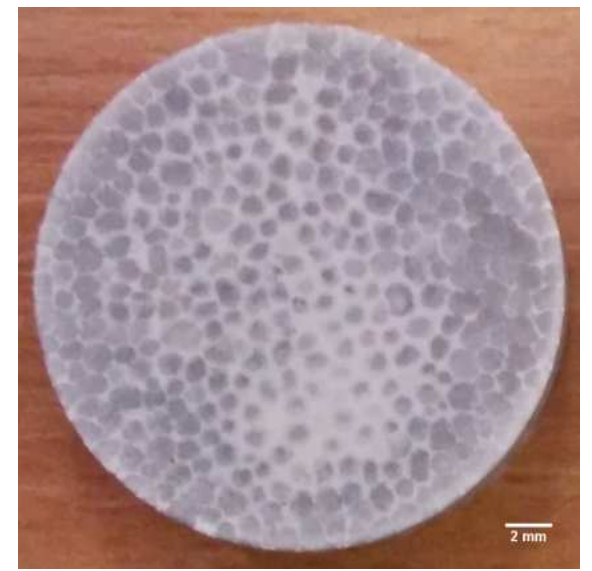

(a)

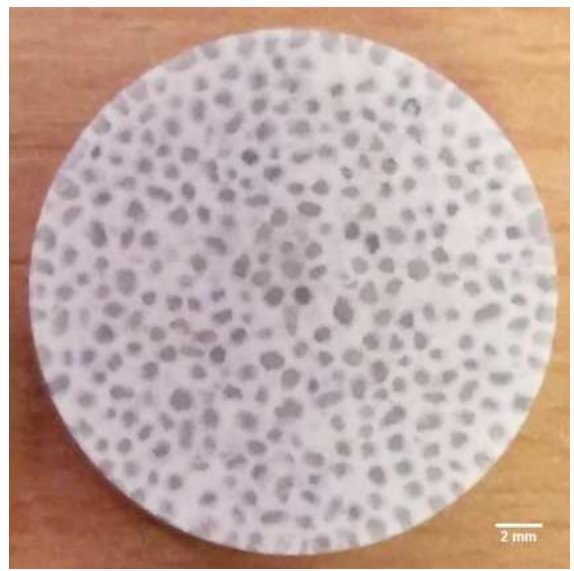

(b)

Figure 5: Bottom surface of compacted pellets made by (a) dry mixing and (b) tapping

Despite "sintering" of the samples above the melting point for PEEK, there was little to no distortion of the pellets, with only a very slight (on average $<0.5 \%$ ) decrease in diameter. Although the PEEK melts, it is likely to be held in the gaps between the salt beads by capillary forces. The high fraction of $\mathrm{NaCl}$ beads lends rigidity to the compact, without them, significant slumping is observed. Measurements of the time required for removal of the salt from the sintered pellets, revealed faster removal from tapped samples as well as lower levels of residual salt, suggesting improved interconnectivity for tapped structures.

\subsection{Porous structures}

It was found that both methods were able to produce a porous structure that was sufficiently robust to be handled. Photograph and CT images of typical porous pellets made by the methods described are given in Figure 6 (in the case of the sample made by tapping the thin PEEK layer on the surface was removed by manual grinding so as not to affect imaging and measurement of the porosity and other structural features). It is clear that in both cases the use of a narrow size range of spherical 
beads, in conjunction with the simple processing route, gives rise to structures with far more uniform pore sizes and structures compared with those presented in Figure 1 for alternative leaching-based processes. For the structures made by tapping, it is also apparent that there are multiple small windows linking the pores.

The mean porosity for a batch of 10 samples made by dry mixing was $79 \%$, with a standard deviation of $1.3 \%$. For tapping, the mean porosity was $84 \%$ with a standard deviation of $0.5 \%$. The lower standard deviation for the tapped structures demonstrates the capability for improved reproducibility in porosity for this process. The targeted porosity, based on the $1 / 6$ weight ratio was $83 \%$, the discrepancy between actual and target densities in the case of the dry mixed samples is due to a decrease in bead volume owing to their densification during compaction. In the case of the tapped samples, although the same bead compaction behaviour is relevant, the higher porosity is a result of incomplete interspersion of PEEK and the $\mathrm{NaCl}$ (manifested by the PEEK surface layer).

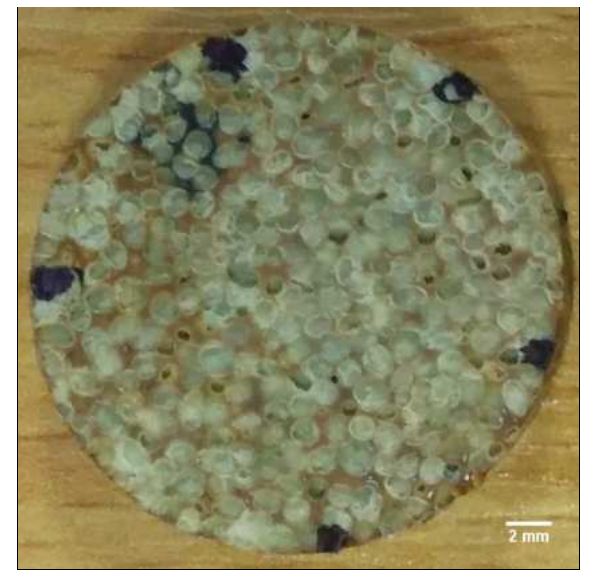

(a)

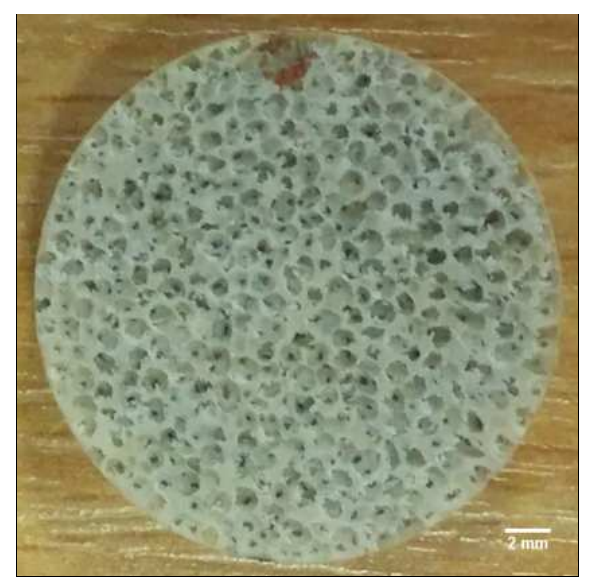

(c)

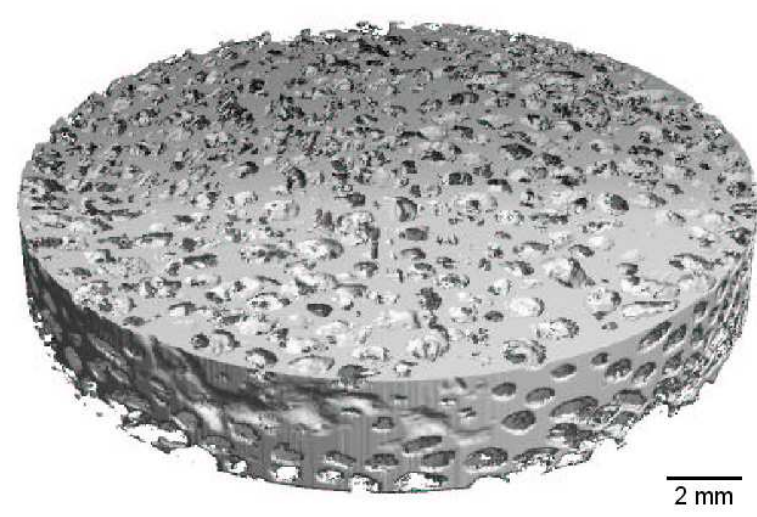

(b)

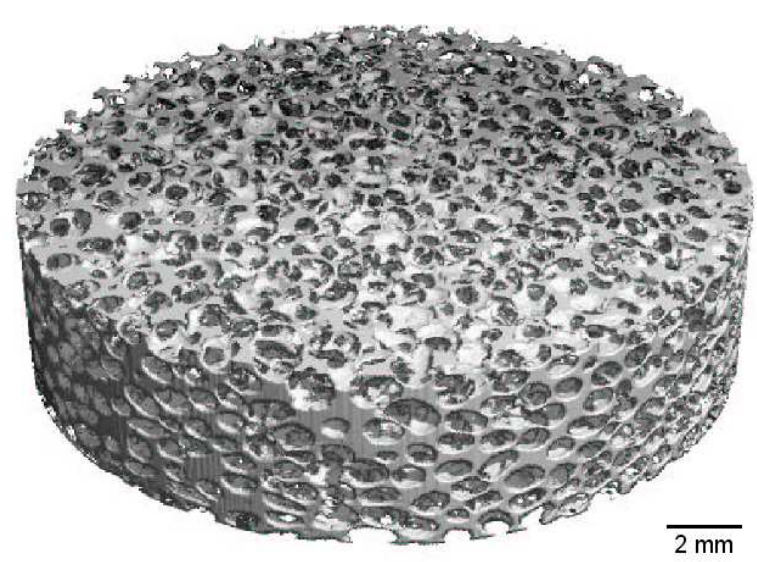

(d)

Figure 6: Porous PEEK samples manufactured by dry mixing $(a, b)$ and tapping $(c, d)$ 
Figure 7 presents the porosity distribution for typical porous samples taken from area fraction data from circa $1502 \mathrm{D}$ sections obtained by $\mathrm{CT}$. To enable close comparison, the porosity is normalised with respect to the mean value. The improved homogeneity of porosity within the structure made by tapping is clear. The variation in porosity with height is very uniform for the tapped sample, with a standard deviation of only $1.2 \%$. For the sample made by dry mixing, the porosity level is much more variable, with a standard deviation of $7.0 \%$, and shows a clear tendency for a PEEK-rich layer to form at the top surface and for salt bead segregation to the base, a reflection of the difficulty in achieving homogeneous mixing of the two phases, which have a large size ratio (22:1) and the difficulty in delivering a homogeneous mixture of powders to the die.

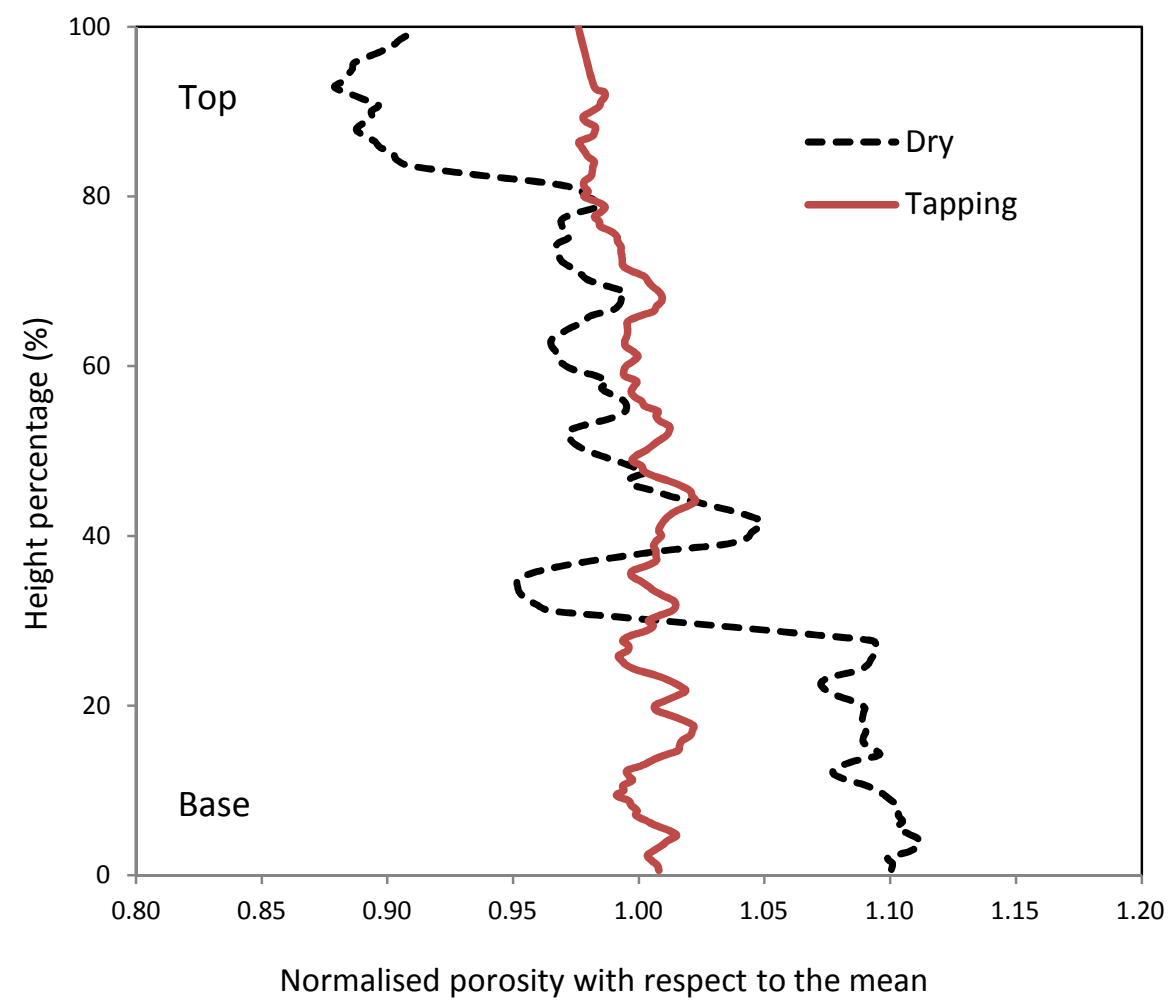

Figure 7: The variation in normalised porosity with sample height

Figure 8 shows, more clearly, that samples produced by the tapping process exhibit windows linking adjacent pores and that this connectivity, in terms of the size and number of windows, is similar from pore-to-pore, throughout the structure. The same connectivity is not apparent in the samples made by dry mixing but, nonetheless, must be present in some form since close to all the salt is removed from the sample during the dissolution step. The "window" connections between pores are formed due to the inability of the PEEK powder (even after melting) to penetrate the regions between and in the vicinity of contacting salt beads. The number of connections is dictated by the coordination number for packing of the beads, which is between 5 and 6 for loose and dense random packing [27-28]. Typically 2 to 3 such windows can be seen in sectioned pores. The mean diameter of these windows, which is difficult to measure when observed away from normal to the viewing axis, is estimated to be between $250-350 \mu \mathrm{m}$, but with a large standard deviation. Although 
the porous structures made by tapping clearly have large "primary" pores, broadly defined by the geometry of the salt beads, the windows which control the interconnectivity of this structure are within the broad range expected for enabling cell growth and migration [29] and resultant bone ingrowth [13].

A simple geometrical model can be used to estimate the "window size" between contacting spheres based on the closest proximity that a smaller sphere can pack between two larger ones. As scatter in the range of possible hole sizes will result from the range in bead sizes and the range in PEEK powder size. Taking the median for both, a window diameter of $314 \mu \mathrm{m}$ is predicted (although the scatter for the full range of possibilities is $190-456 \mu \mathrm{m}$ ).

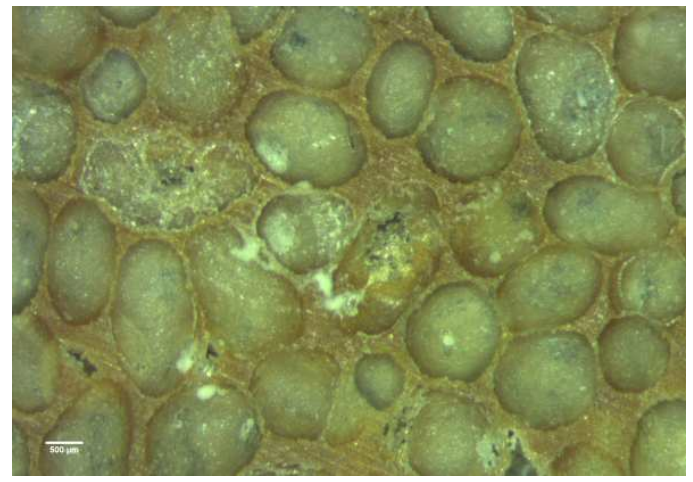

(a)

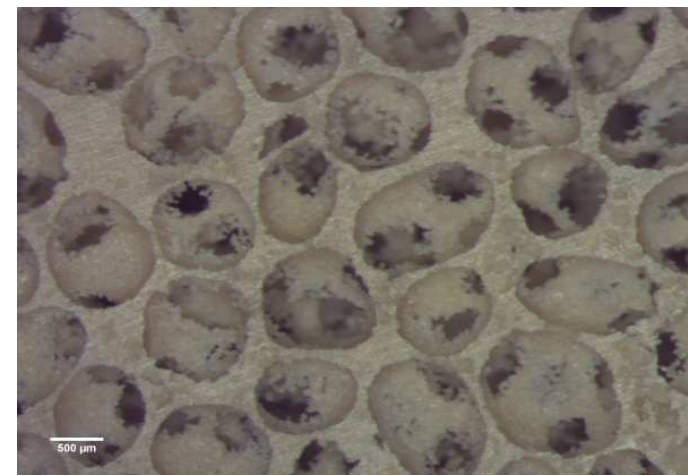

(b)

Figure 8: Optical micrographs of the top surface of porous PEEK structures fabricated by (a) dry mixing and (b) tapping.

Figure 9 compares the microstructures for the porous PEEK made by the two routes. It is evident in both cases that the pores have been flattened by the compaction process to become elongated perpendicular to the compaction direction. At this higher level of magnification, connections between the pores in the structure made by dry mixing can be observed, some are very small, and others very large, a result of the inhomogeneous mixing behaviour for the two components and the potential for PEEK powder to surround the salt beads. In both cases, fusion of the PEEK particles has occurred resulting in dense struts such that the porosity measured will predominantly be in the form of large pores, controlled by the bead size, rather than small open or closed pores within the struts and cell walls. The pore structures (their uniformity and connectivity) resemble those shown in Figure $1 \mathrm{a}$, that were also made using spherical porogens, but it should be noted that the struts in porous structures made by tapping appear to be significantly more dense than those in Figure $1 \mathrm{~b}$, in particular, produced by drying of a polymer solution.

The pore size distributions for the porous PEEK, measured using CT, are presented in Figure 10. These measurements, which are also summarised in Table 1 along with other structural parameters measured by CT, clearly show that the mean (and modal) pore sizes for the two processes are similar, which is to be expected given the same beads sizes were used. There does, however, appear to be a larger fraction of smaller pores for the structures made by dry mixing, which is reflected in the higher standard deviation in the mean value. It is likely that small unfilled regions may exist between clustered $\mathrm{NaCl}$ beads produced by dry mixing that may not be penetrated by the molten 
PEEK, skewing the pore size distribution to lower values. The mean and maximum strut thickness, and standard deviation in the mean, indicates that a higher level of structural inhomogeneity exists for samples made by dry mixing, owing to the greater variability in the inter-bead spacing for a randomly mixed powder system.

It should be noted, however, that these pore size measurements do not correspond closely with the original bead sizes. The pore size is determined by the $\mathrm{CT}$ instrument by filling the pores with the largest sphere possible, which for the compacted beads form pores with a prolate spheroid shape, will approximate to the minor axis (parallel to the axis of compaction). The degree of anisotropy, measured by CT is close to 1.5 for both processes. The origin of the elongation is of course the compaction process which is similar for both processes. It should also be noted that the porous salt spheres are compressible and are able to reduce in volume (by an estimated $15 \%$ ) during the compaction process. Inspection of the lower magnification images in Figure 9 support a reduction in the bead size during processing.

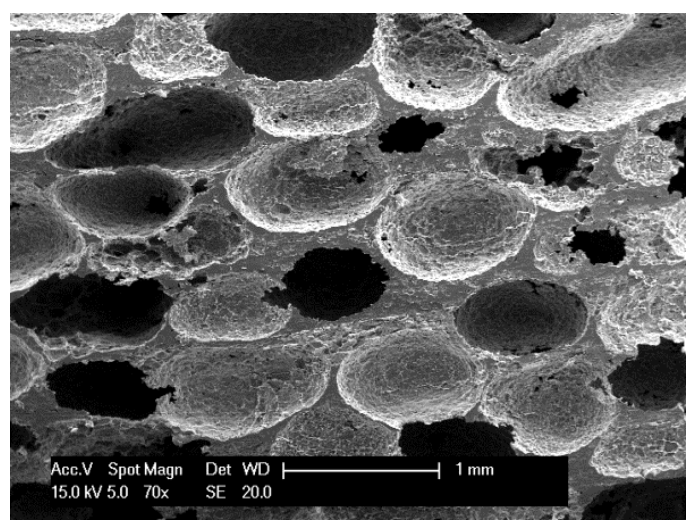

(A)

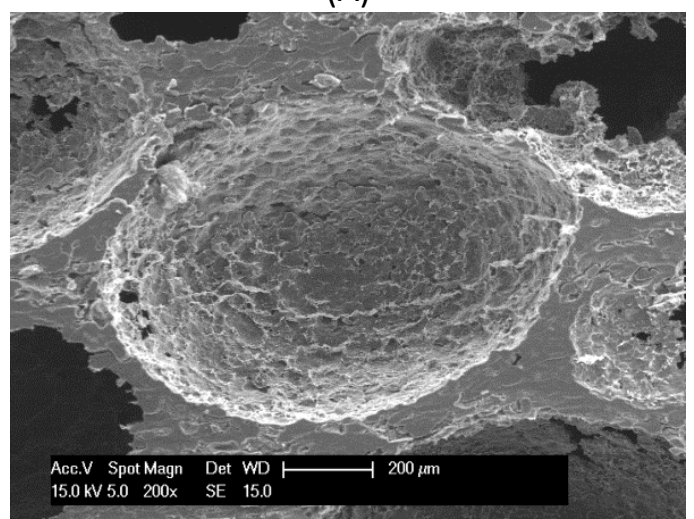

(C)

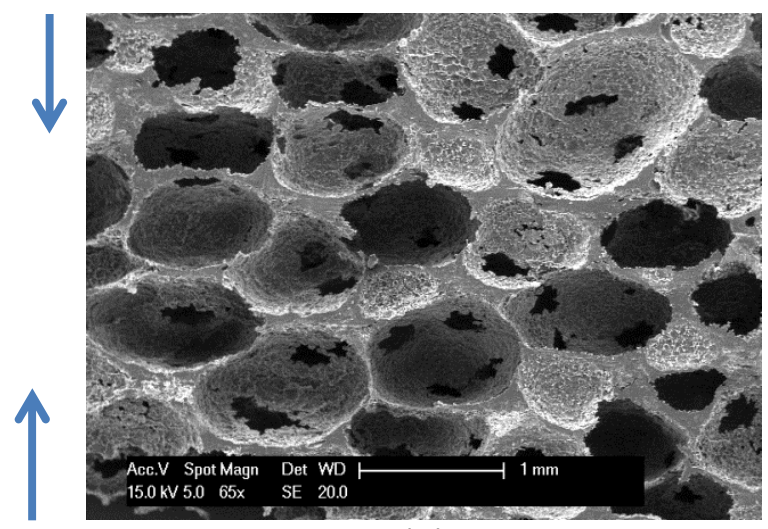

(B)

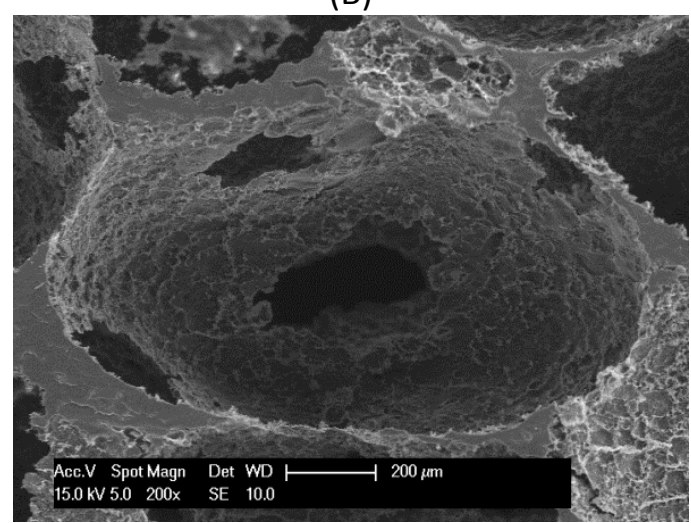

(D)

Figure 9: SEM images of vertical cross sections of porous PEEK structures fabricated by $(a, c)$ dry mixing and $(b, d)$ tapping. The arrows in the image show the compaction direction for all cases.

The connectivity density, which represents the ratio of the connecting holes, vertices (end points), and struts (bridges) in one unit volume, is also presented, which for dry and tapping processes are close to 9 and 6 per $\mathrm{mm}^{3}$, respectively. Thomsen et al [30] stated that human bone has a 
connectivity density less than 12 per $\mathrm{mm}^{3}$, and Kabel et al [31] found that in samples of humans between 14 and 91 years old, the connectivity density varied between 1 and 9 with a mean close to 3. The connectivity density measurements, in particular for the tapped structure, are in keeping with those expected for a material designed to resemble the structure of trabecular bone and suggested targets of 7 per $\mathrm{mm}^{3}[1]$.

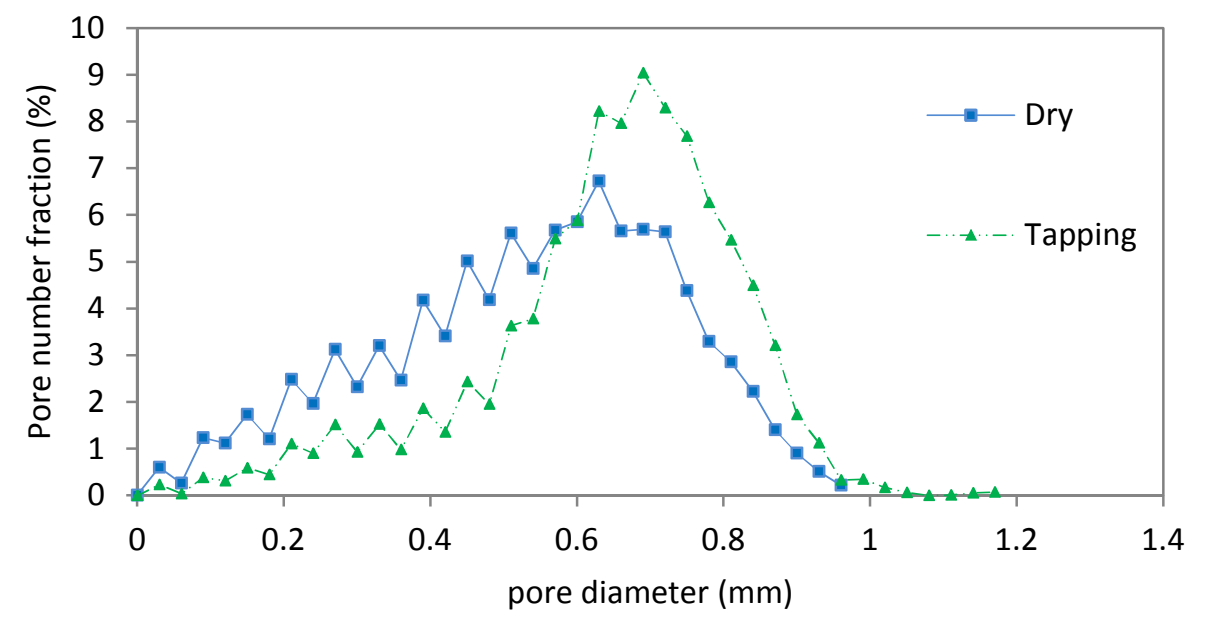

Figure 10: Pore size distribution comparison for dry and tapped structures

Table 1: Structural parameters for porous PEEK measured by CT

\begin{tabular}{|l|c|c|}
\hline Manufacturing method & DRY & TAPPED \\
\hline Mode of pore size $(\mathrm{mm})$ & 0.63 & 0.69 \\
\hline Mean pore size $(\mathrm{mm})$ & 0.54 & 0.58 \\
\hline Standard deviation of the mean pore size $(\mathrm{mm})$ & 0.20 & 0.16 \\
\hline Mean strut thickness $(\mathrm{mm})$ & 0.24 & 0.17 \\
\hline Standard deviation of the mean strut thickness $(\mathrm{mm})$ & 0.16 & 0.07 \\
\hline Maximum strut thickness $(\mathrm{mm})$ & 1.17 & 0.63 \\
\hline Degree of anisotropy & 1.52 & 1.50 \\
\hline Connectivity density $\left(1 / \mathrm{mm}^{3}\right)$ & 9.22 & 6.43 \\
\hline
\end{tabular}

\subsection{Benefits of the tapping process}

The tapping process creates a stable and fairly densely packed $\mathrm{NaCl}$ bead structure before the PEEK is introduced and then facilitates the migration of the (relatively) fine PEEK powder through the network of channels between the beads. Using spherical beads with a reasonably tight size range results in a homogenous network that is unlikely to have inaccessible areas of clustered porogen (as is likely to be the case for angular particles with a wide size distribution). The tapping process also pre-establishes the inter-particle contacts which are well-defined due to the repeatable and predictable loose or dense random packing characteristics for near-monosized spherical particles 
$[27,28]$. The level of interconnectivity achieved by tapping is sufficient, as measured by the connectivity density, to not require an additional sintering step.

This is in stark contrast to the highly variable quality of mixing of powders with a large size difference and the segregation problems associated with flow and transfer of these mixtures. Although the use of binders or compounding can create improved distributions of the two powders and may overcome segregation of the fine powder, it will prevent direct bead-bead contact and hence greatly reduce the interconnectivity. The benefit of pre-establishing the network of $\mathrm{NaCl}$ beads is borne out in improved repeatability and homogeneity of density and pore size, an improved and predictable level of connectivity, faster $\mathrm{NaCl}$ removal rates and lower levels of residual salt. Figure 11 shows 3D $X$-ray tomographic reconstructions of the full sample thickness, highlighting the residual salt (bright). Not only is the salt level much lower in the sample made by tapping (estimated from image analysis to be $<0.1 \%$ of the pore volume) but the high levels of salt in the mixed samples (estimated to be $>$ $12 \%$ of the pore volume) remain there after more than $72 \mathrm{hr}$ of immersion (compared with $4 \mathrm{hr}$ for the tapped sample).

It is clear that the tapping route, whilst less convenient, produces structures with the not only the characteristic structures, but also with the quality and reproducibility demanded. For the bead size used (1.0 to $1.4 \mathrm{~mm}$ diameter), consolidation and elongation of the beads has produced porosity that is close to, but slightly larger than the target size $(700 \mu \mathrm{m})$ achieving a good compromise in terms of the size of the windows between the pores, strut thickness and connectivity density. If required, pore sizes and windows could be further tailored by altering the size and size distribution for the beads used, with a requisite reduction in the size of the "filler" powder as the salt bead size decreases. The ability to vary the pore fraction is more limited. Since the process "fills" the available space within the packed bead structure (a reduced number of tapping cycles only part-fills the structure and excess PEEK simply remains on the top surface), porosity is dictated by the packing behaviour of the beads and of the PEEK. If the porosity level needed to be increased (for the same bead size and type) an increase in the PEEK powder size would affect this through less efficient filling of the void spaces.

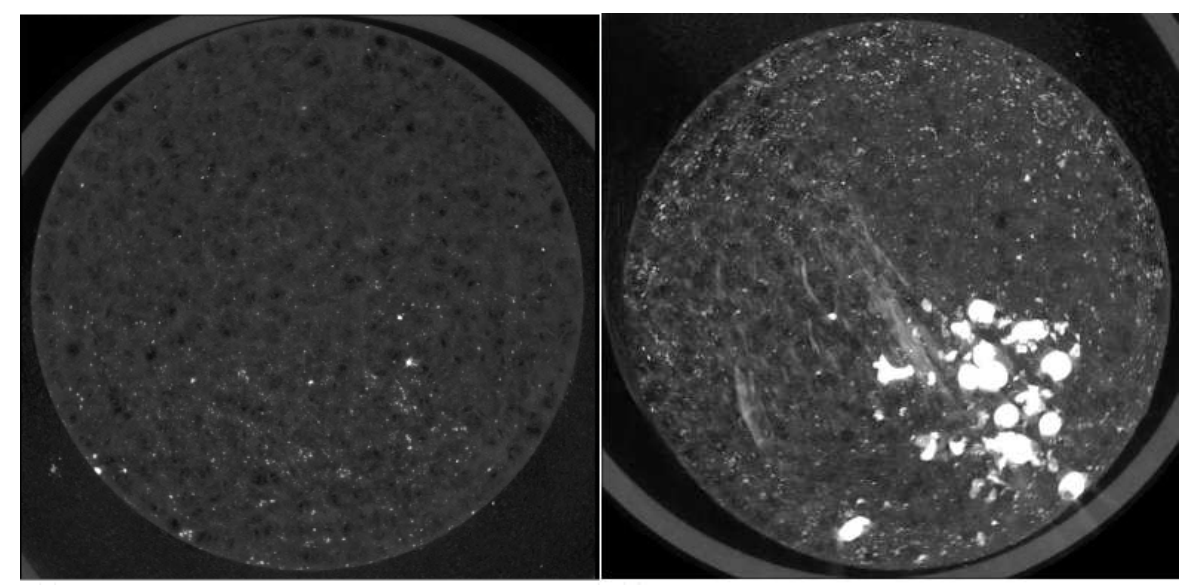

(a)

(b)

Figure 11: 3D views through the porous structures highlighting the residual salt (bright) in structures made by (a) tapping and (b) dry mixing. 


\subsection{Mechanical testing}

Figure 12 presents stress - strain curves for a dry mixed sample, with a porosity of $79.7 \%$ (relative density, $\mathrm{RD}$, of 0.20$)$ and a tapped sample with a porosity of $84.5 \%(\mathrm{RD}=0.16)$. The stress-strain curves are typical of those for the samples tested, showing an initial peak, taken as the compressive strength, followed by a plateau region which is flatter for samples with lower densities. Densification of the porous structures commences at strains of approximately $60 \%$. Table 2 summarises the mechanical properties for porous structures made by the two methods, expressing them as averages over the batch of samples tested. The samples produced by dry mixing, with the higher density, show higher compressive yield strengths and significantly higher stiffnesses. Whilst samples made by both methods demonstrate average compressive yield stresses close to or slightly above those for typical lumbar loads, the strength and stiffness are well below those for trabecular bone (36 MPa and 1-10 GPa respectively $[1,13])$. As a consequence, it is expected that these structures will be designed to be non-load bearing elements within hybrid structures or complex devices.

Table 2: Mechanical property data for porous PEEK samples

\begin{tabular}{|l|l|l|l|l|}
\hline Sample & Porosity / \% & RD & E / MPa & Yield Strength / MPa \\
\hline Dry mix & $79.2 \pm 1.3$ & 0.21 & $65.6 \pm 8.9$ & $1.85 \pm 0.3$ \\
\hline Tapped & $83.9 \pm 0.5$ & 0.16 & $39.2 \pm 4.0$ & $1.22 \pm 0.2$ \\
\hline
\end{tabular}

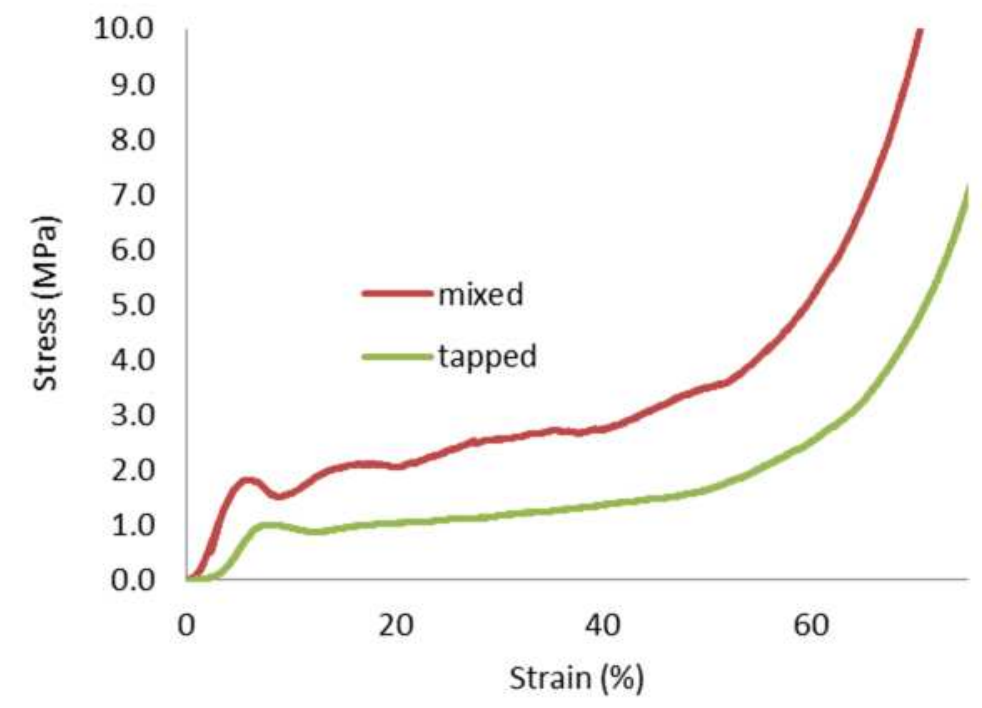

Figure 12: Typical stress-stain curves for mixed $(R D=0.21)$ and tapped $(R D=0.16)$ structures

Within the samples tested for each manufacturing method there is variability in the density. Although the range of densities explored is rather limited and extrapolation should be taken with some caution, plots of normalised strength or stiffness against relative density can be produced and, through fitting 
to simple models, a comparison between equivalent samples (those with the same relative density) made by the two processing routes can be made. Scaling laws for stiffness and yield strength, with respect to the relative density and properties of the solid, s, are given in equations 1 and 2, for open cell foams [12], where only the strengthening or stiffening due to deformation of the cell edges is considered.

$$
\begin{aligned}
& \frac{E}{E_{S}}=C_{1}\left(\frac{\rho}{\rho_{s}}\right)^{2} \\
& \frac{\sigma}{\sigma_{s}}=C_{2}\left(\frac{\rho}{\rho_{s}}\right)^{3 / 2}
\end{aligned}
$$

Figures 13 and 14 plot the stiffness and strength data as a function of the relative density. Fit lines to a power law of the type shown in equations 1 and 2 are also shown, as are the fit values. The power exponents are close to the model values for the samples made by dry mixing ( 1.9 and 1.6 for stiffness and strength respectively), but is significantly higher in both cases for the tapped structures (3.1 and 4.2 for stiffness and strength respectively), indicating a stronger reduction in the stiffness and strength with increasing porosity. This difference is thought to be due to structural differences, principally as a result of the large windows in the cell walls that are present in the tapped structures (although it should be noted that residual salt in the mixed samples may contribute to the strength and stiffness). The fit to the open cell model is better for samples made by tapping and for the stiffness data, supporting the increased contribution of the cell walls to the strength for samples made by mixing (with no large windows in the cell walls) and the more harmful effect of cell wall porosity on stiffness [32].

Although the study presents a fair measurement of the compressive properties for samples that are typical of the scale required in a medical device and a fair comparison between the two manufacturing processes, caution should be taken to extrapolate these trends beyond the data reported here, given not only the small interval of densities studied, but additionally that the sample thickness is below the minimum recommended to show independence of properties with thickness (typically 8 times the cell diameter [33]). 


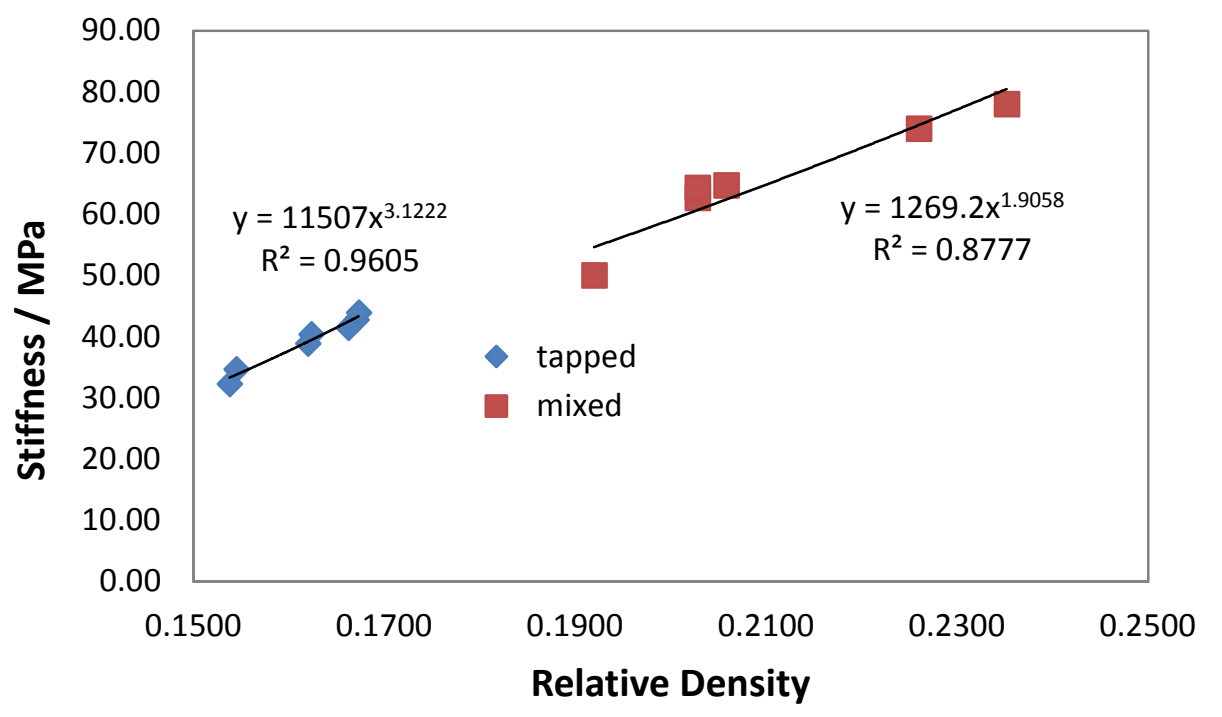

Figure 13: Plot of stiffness vs relative density and fit to an open cell power law model

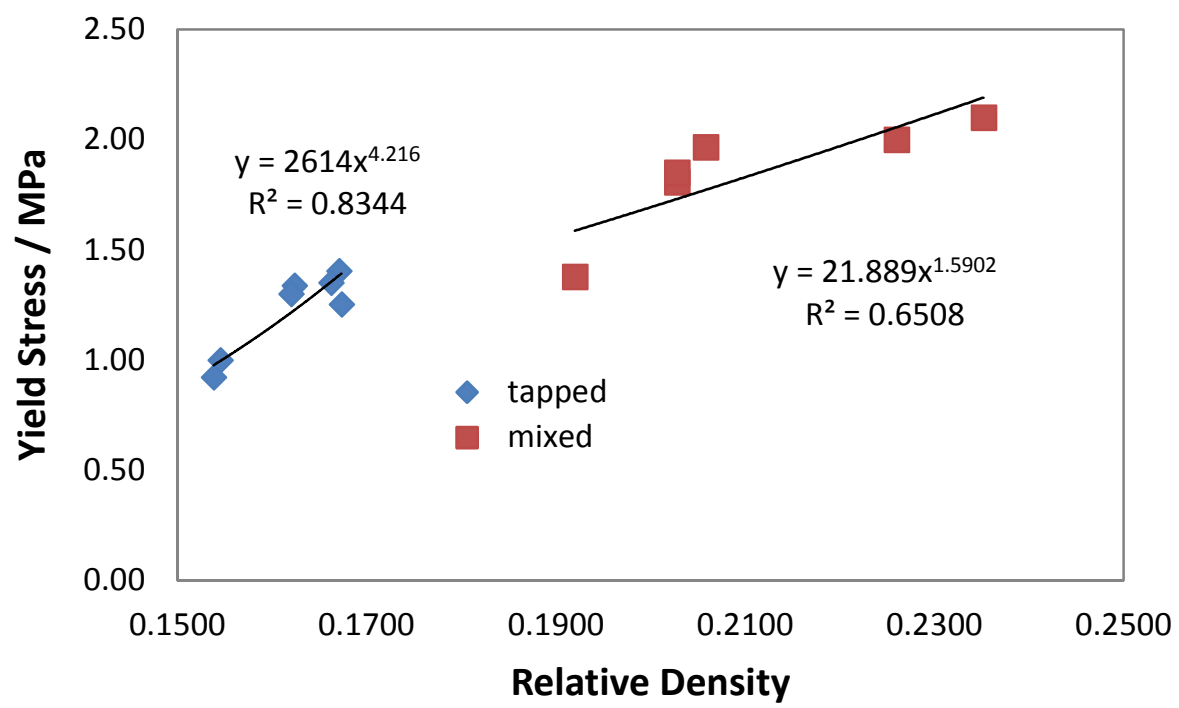

Figure 14: Plot of compressive strength vs relative density and fit to an open cell power law model

\section{Conclusions}

Porous PEEK structures were produced by two methods, both using near-spherical salt beads. The use of near-spherical beads with a fairly narrow size range results in uniform pore structures.

The integration, by tapping, of fine PEEK into a pre-existing network of 1.0-1.4 mm diameter salt beads, followed by compaction and "sintering", produces porous structures typified by slightly 
elliptical pores, elongated normal to the compaction direction, with 5 to 6 , approximately $300 \mu \mathrm{m}$ diameter windows connecting each pore with its neighbours.

Pre-establishing the contacts between the salt beads, before addition of the PEEK powder, results in: structures with improved repeatability and homogeneity of density, more uniform pore and strut sizes, an improved and predictable level of connectivity, faster $\mathrm{NaCl}$ removal rates and lower levels of residual salt.

Porous structures produced by tapping and with $84 \%$ porosity, show a compressive yield stress $>1$ $\mathrm{MPa}$ and stiffness $>30 \mathrm{MPa}$. The presence of windows in the cell walls, however, means that for samples with the same relative density, tapped structures will show lower strengths and stiffnesses compared with those made by dry mixing.

\section{Acknowledgements}

ARS would like to thank the Directorate General Higher Education of Indonesia (DGHE / DIKTI) and UIN Sultan Syarif Kasyim Riau for PhD funding. The authors would like to acknowledge financial support, useful discussions and the supply of materials (PEEK) from Invibio Ltd.

\section{References}

1. Jarman-Smith, M., M. Brady, S.M. Kurtz, N.M. Cordaro, and W.R. Walsh, Chapter 12 Porosity in Polyaryletheretherketone, in PEEK Biomaterials Handbook. 2012, William Andrew Publishing: Oxford. p. 181-199.

2. Schmidt, M., D. Pohle, and T. Rechtenwald, Selective Laser Sintering of PEEK. CIRP Annals Manufacturing Technology, 2007. 56(1): p. 205-208.

3. Kurtz, S.M., ed. PEEK biomaterial handbooks. 2012, Elsevier.

4. Kurtz, S.M. and J.N. Devine, PEEK biomaterials in trauma, orthopedic, and spinal implants. Biomaterials, 2007. 28(32): p. 4845-4869.

5. Jaekel, D.J., D.W. MacDonald, and S.M. Kurtz, Characterization of PEEK biomaterials using the small punch test. Journal of the Mechanical Behavior of Biomedical Materials, 2011. 4(7): p. $1275-1282$.

6. $\quad$ Kurtz, S.M., Chapter 6 - Chemical and Radiation Stability of PEEK, in PEEK Biomaterials Handbook. 2012, William Andrew Publishing: Oxford. p. 75-79.

7. Converse, G.L., T.L. Conrad, C.H. Merrill, and R.K. Roeder, Hydroxyapatite whisker-reinforced polyetherketoneketone bone ingrowth scaffolds. Acta Biomaterialia, 2010. 6(3): p. 856-863. 
8. Moskalewicz, T., S. Seuss, and A.R. Boccaccini, Microstructure and properties of composite polyetheretherketone/Bioglass ${ }^{\circledR}$ coatings deposited on Ti-6Al-7Nb alloy for medical applications. Applied Surface Science, 2013. 273(0): p. 62-67.

9. J M Toth, M Wang, B T Estes, J L Seifert, H B Seim $3^{\text {rd }}$, A S Turner, PEEK as a biomaterial for spinal applications, Biomaterials, 27 (3) 2006, 324-334.

10. Douglas G. Orndorff, M.A.S., Katie A. Patty, Force Transfer in the Spine. Journal of The Spinal Research Foundation, 2012. 7(2): p. 30-35.

11. Jensen, G.M., Biomechanics of the Lumbar Intervertebral Disk: A Review. 1980. 60: p. 765773.

12. M. F. Ashby, A.G.Evans., N. A. Fleck, L. J. Gibson, J. W. Hutchinson, and H. N. G. Wadley, Metal Foams: A Design Guide. 2000, Boston, Mass, USA: Butterworth Heinemann.

13. Ryan, G., A. Pandit, and D.P. Apatsidis, Fabrication methods of porous metals for use in orthopaedic applications. Biomaterials, 2006. 27(13): p. 2651-2670.

14. Hou, Q., D.W. Grijpma, and J. Feijen, Porous polymeric structures for tissue engineering prepared by a coagulation, compression moulding and salt leaching technique. Biomaterials, 2003. 24(11): p. 1937-1947.

15. Reignier, J. and M.A. Huneault, Preparation of interconnected poly( $\varepsilon$-caprolactone) porous scaffolds by a combination of polymer and salt particulate leaching. Polymer, 2006. 47(13): p. $4703-4717$.

16. Cannillo, V., F. Chiellini, P. Fabbri, and A. Sola, Production of Bioglass ${ }^{\circledR} 45 S 5-$ Polycaprolactone composite scaffolds via salt-leaching. Composite Structures, 2010. 92(8): p. 1823-1832.

17. Heijkants, R.G.J.C., T.G. Tienen, J.H. Groot, A.J. Pennings, P. Buma, R.P.H. Veth, and A.J. Schouten, Preparation of a polyurethane scaffold for tissue engineering made by a combination of salt leaching and freeze-drying of dioxane. Journal of Materials Science, 2006. 41(8): p. 2423-2428.

18. El-Kady, A.M., R.A. Rizk, B.M. Abd El-Hady, M.W. Shafaa, and M.M. Ahmed, Characterization, and antibacterial properties of novel silver releasing nanocomposite scaffolds fabricated by the gas foaming/salt-leaching technique. Journal of Genetic Engineering and Biotechnology, 2012. 10(2): p. 229-238.

19. Kim, T.G., H.J. Chung, and T.G. Park, Macroporous and nanofibrous hyaluronic acid/collagen hybrid scaffold fabricated by concurrent electrospinning and deposition/leaching of salt particles. Acta Biomaterialia, 2008. 4(6): p. 1611-1619.

20. Flaibani, M. and N. Elvassore, Gas anti-solvent precipitation assisted salt leaching for generation of micro- and nano-porous wall in bio-polymeric 3D scaffolds. Materials Science and Engineering: C, 2012. 32(6): p. 1632-1639.

21. Cai, Q., J. Yang, J. Bei, and S. Wang, A novel porous cells scaffold made of polylactide-dextran blend by combining phase-separation and particle-leaching techniques. Biomaterials, 2002. 23(23): p. 4483-4492. 
22. Zhang, J., Wu L., D Jing., J Ding., A comparative study of porous scaffolds with cubic and spherical macropores. Polymer, 2005. 46(13): p. 4979-4985.

23. Gross, K.A. and L.M. Rodríguez-Lorenzo, Biodegradable composite scaffolds with an interconnected spherical network for bone tissue engineering. Biomaterials, 2004. 25(20): p. 4955-4962.

24. Petrovic, L., D. Pohle, H. Münstedt, T. Rechtenwald, K.A. Schlegel, and S. Rupprecht, Effect of BTCP filled polyetheretherketone on osteoblast cell proliferation in vitro. Journal of Biomedical Science, 2006. 13(1): p. 41-46.

25. Jinnapat, A. and A. Kennedy, The manufacture of spherical salt beads and their use as dissolvable templates for the production of cellular solids via a powder metallurgy route. Jounal of Alloys and Compounds, 2010. 499: p. 43-47.

26. Jinnapat, A. and A. Kennedy, The manufacture and characterisation of aluminium foams made by investment casting using dissolvable spherical sodium chloride bead preforms, in Department of Mechanical, Materials and Manufacturing Engineering. 2011, University of Nottingham.

27. Jerier, J.-F., V. Richefeu, D. Imbault, and F.-V. Donzé, Packing spherical discrete elements for large scale simulations. Computer Methods in Applied Mechanics and Engineering, 2010. 199(25-28): p. 1668-1676.

28. Van Antwerpen, W., C.G. Du Toit, and P.G. Rousseau, A review of correlations to model the packing structure and effective thermal conductivity in packed beds of mono-sized spherical particles. Nuclear Engineering and Design, 2010. 240(7): p. 1803-1818.

29. Lee, J.-S., H.D. Cha, J.-H. Shim, J.W. Jung, J.Y. Kim, and D.-W. Cho, Effect of pore architecture and stacking direction on mechanical properties of solid freeform fabrication-based scaffold for bone tissue engineering. Journal of Biomedical Materials Research Part A, 2012. 100A(7): p. 1846-1853.

30. Thomsen, J.S., J. Barlach, and L. Mosekilde, Determination of connectivity density in human iliac crest bone biopsies assessed by a computerized method. Bone, 1996. 18(5): p. 459-465.

31. Kabel, J., A. Odgaard, B. van Rietbergen, and R. Huiskes, Connectivity and the elastic properties of cancellous bone. Bone. 24(2): p. 115-120.

32. Deng X., G. B. Piotrowski, J. J. Williams, N. Chawla, Effect of porosity and tensioncompression asymmetry on the Bauschinger effect in porous sintered steels. International Journal of Fatigue, 2005. 27(10-12): p. 1233-1243.

33. Andrews, E.W., et al., Size effects in ductile cellular solids. Part II: experimental results. International Journal of Mechanical Sciences, 2001. 43(3): p. 701-713. 


\section{Vitae}

\section{Dr Andrew Kennedy}

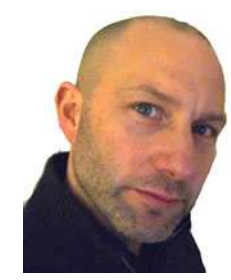

Andrew Kennedy graduated from Imperial College, London in 1989, before studying for a Ph.D. at Cambridge University. Upon completion, he joined the academic staff at Nottingham University, where he remains. He is a member of the Manufacturing Research Division with expertise in light alloys and powder processing. His core research activity is in the field of multi-phase materials, with the main emphasis on processing-structure-property relationships in metal-ceramic composites and porous materials. He is a Fellow of the Institute of Materials, Minerals and Mining $\left(\mathrm{IOM}^{3}\right)$ and a Chartered Engineer.

Mr Abdur Rahman Siddiq

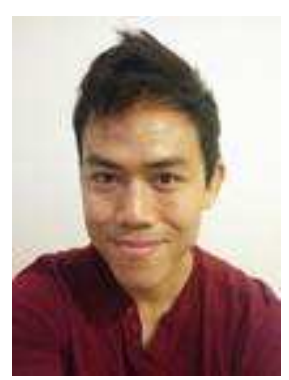

Abdur Rahman Siddiq graduated from the Institute of Technology of Bandung, Indonesia in 2004 and started working as a junior staff member for UIN Sultan Syarif Kasim Riau, Pekanbaru, in the Department of Industrial Engineering from 2005 until 2010. He is currently studying at the University of Nottingham for a PhD in Manufacturing Engineering, sponsored by Invibio, Ltd and the Directorate General of Higher Education of Indonesia (DGHE / DIKTI ). He is a member of the Institute of Materials, Minerals and Mining $\left(\mathrm{IOM}^{3}\right)$. 
